Review

\title{
Probiotics (Direct-Fed Microbials) in Poultry Nutrition and Their Effects on Nutrient Utilization, Growth and Laying Performance, and Gut Health: A Systematic Review
}

\author{
Rajesh Jha *®D, Razib Das $₫$, Sophia Oak and Pravin Mishra $₫$ \\ Department of Human Nutrition, Food and Animal Sciences, College of Tropical Agriculture and Human \\ Resources, University of Hawaii at Manoa, Honolulu, HI 96822, USA; dasrazib@hawaii.edu (R.D.); \\ sophia.oak@gmail.com (S.O.); mpravin470@gmail.com (P.M.) \\ * Correspondence: rjha@hawaii.edu
}

Received: 25 August 2020; Accepted: 5 October 2020; Published: 13 October 2020

Simple Summary: Probiotics are live bacteria, fungi, or yeasts that supplement the gastrointestinal flora and help to maintain a healthy digestive system, thereby promoting the growth performance and overall health of poultry. Probiotics are increasingly being included in poultry diets as an alternative to antibiotics. This systematic review provides a summary of the use of probiotics in poultry production and the potential role of probiotics in the nutrient utilization, growth and laying performance, and gut health of poultry.

\begin{abstract}
Probiotics are live microorganisms which, when administered in adequate amounts, confer health benefits to the host. The use of probiotics in poultry has increased steadily over the years due to higher demand for antibiotic-free poultry. The objective of this systematic review is to present and evaluate the effects of probiotics on the nutrient utilization, growth and laying performance, gut histomorphology, immunity, and gut microbiota of poultry. An electronic search was conducted using relevant keywords to include papers pertinent to the topic. Seventeen commonly used probiotic species were critically assessed for their roles in the performance and gut health of poultry under existing commercial production conditions. The results showed that probiotic supplementation could have the following effects: (1) modification of the intestinal microbiota, (2) stimulation of the immune system, (3) reduction in inflammatory reactions, (4) prevention of pathogen colonization, (5) enhancement of growth performance, (6) alteration of the ileal digestibility and total tract apparent digestibility coefficient, and (7) decrease in ammonia and urea excretion. Thus, probiotics can serve as a potential alternative to antibiotic growth promoters in poultry production. However, factors such as the intestinal health condition of birds, the probiotic inclusion level; and the incubation conditions, feedstuff, and water quality offered to birds may affect the outcome. This systematic review provides a summary of the use of probiotics in poultry production, as well as the potential role of probiotics in the nutrient utilization, growth and laying performance, and gut health of poultry.
\end{abstract}

Keywords: chicken; intestinal health; direct-fed microbial; histomorphology; immunology; gut microbiota; nutrition

\section{Introduction}

The European Union-wide ban on the use of antibiotic growth promoters (AGP) in farm animals in 2006 was a stellar step toward tackling the claimed antibiotic resistance issue [1]. Though many jurisdictions followed suit, due to the sparse regulation and lack of quantitative monitoring data on 
AGP, antibiotics have still been used as a growth promoter in many countries [2]. However, with the emerging public health concern about antibiotic resistance, it has become imperative to find an alternative approach to grow healthy animals [3]. Moreover, eliminating the use of antibiotics has spurred considerable consequences such as compromised animal performance and increased incidence of animal diseases [4,5]. Enteric diseases have become one of the prime concerns in the poultry industry after the exclusion of AGP. The industry has been suffering from unsatisfactory production efficiency, bacterial overgrowth in the small intestines, nutrient malabsorption, and associated food contamination [6,7]. Several feed additives in poultry have been tried as an alternative to AGP with varying degrees of success [8]. These commonly used feed additives can be classified into eight principle classes [9]. The key characteristics of each feed additive are summarized in Table 1. Of the eight feed additives classes, probiotics have gained worldwide recognition for improving broiler health and growth.

Table 1. Advantages and disadvantages of eight classes of feed additives used as an alternative to antibiotic growth promoters (AGP) in poultry production.

\begin{tabular}{|c|c|c|c|}
\hline Alternative to AGP & Description & Advantages & Disadvantages \\
\hline Probiotics & $\begin{array}{l}\text { Live bacteria and yeasts that } \\
\text { provide health benefits }\end{array}$ & $\begin{array}{ll}\text { - } & \text { Improves digestion } \\
\text { - } & \text { Strengthens immunity }\end{array}$ & $\begin{array}{l}\text { - } \quad \text { Strain and dose-dependent } \\
\text { - } \quad \text { Possible adverse side effects }\end{array}$ \\
\hline Prebiotics & $\begin{array}{l}\text { Non-digestible fibers that } \\
\text { stimulate growth or activity of } \\
\text { certain healthy bacteria }\end{array}$ & $\begin{array}{l}\text { - } \quad \text { Improves mineral absorption } \\
\text { - } \quad \text { Enhances immune function }\end{array}$ & $\begin{array}{ll}\text { - } & \text { Dose-dependent } \\
\text { - } & \text { Possible adverse side effects }\end{array}$ \\
\hline Hyperimmune IgY & $\begin{array}{l}\text { An antibody that helps transfer } \\
\text { passive immunity }\end{array}$ & $\begin{array}{ll}\text { - } & \text { Environmentally friendly } \\
\text { Reduces the number of animals } \\
\text { required for antibody production }\end{array}$ & $\begin{array}{l}\text { - } \quad \begin{array}{l}\text { Susceptibility to proteolytic } \\
\text { degradation in the gut }\end{array} \\
\text { - } \quad \text { High manufacturing costs }\end{array}$ \\
\hline Antimicrobial Peptides & $\begin{array}{l}\text { Proteins with broad-spectrum } \\
\text { antimicrobial activities against } \\
\text { bacteria, viruses, and fungi }\end{array}$ & - $\quad$ Broad-spectrum beneficial activity & $\begin{array}{ll}\text { - } & \text { High manufacturing costs } \\
\text { - } & \text { Systemic and local toxicity } \\
\text { - } & \text { Susceptibility to proteolysis } \\
\text { - } & \text { Natural resistance }\end{array}$ \\
\hline Organic Acids & $\begin{array}{l}\text { Different acids that have } \\
\text { antimicrobial activity }\end{array}$ & $\begin{array}{l}\text { - Improves growth performance } \\
\text { - } \quad \text { Strengthens immunity }\end{array}$ & $\begin{array}{l}\text { - } \quad \text { Dose-dependent } \\
\text { - } \quad \text { Possible adverse side effects }\end{array}$ \\
\hline $\begin{array}{l}\text { Phytogenics (Oleoresin, } \\
\text { Essential oils) }\end{array}$ & $\begin{array}{l}\text { Natural growth promoters or } \\
\text { non-AGPs used as feed additives } \\
\text { derived from herbs, spices, or } \\
\text { other plants }\end{array}$ & - Improves growth performance & $\begin{array}{l}\text { Potential interactions } \\
\text { with bacteria }\end{array}$ \\
\hline Enzymes & $\begin{array}{l}\text { Exogenous feed enzymes that } \\
\text { break down fiber and other } \\
\text { (anti-nutritional) components of } \\
\text { the diet-e.g., phytate }\end{array}$ & $\begin{array}{l}\text { - } \quad \text { Improves growth performance } \\
\text { - } \quad \text { Strengthens immunity }\end{array}$ & $\begin{array}{l}\text { - Highly sensitive to } \\
\text { the environment }\end{array}$ \\
\hline Clay & $\begin{array}{l}\text { Supplements used as a binding } \\
\text { and lubricating agent in the } \\
\text { production of pelleted feeds }\end{array}$ & $\begin{array}{l}\text { - } \quad \text { Enhances growth performance } \\
\text { - Combats bacterial infections } \\
\text { in poultry }\end{array}$ & $\begin{array}{l}\text { - } \quad \text { Potential interactions } \\
\text { with bacteria } \\
\text { - } \quad \text { Possible adverse side effects }\end{array}$ \\
\hline
\end{tabular}

Probiotics are live bacteria, fungi, or yeasts that supplement the gastrointestinal flora and help to maintain a healthy digestive system. The joint Food and Agriculture Organization of the United Nations (FAO) and World Health Organization (WHO) working group have defined probiotics as "live microorganisms that, when administered in adequate amounts, confers a health benefit on the host" [10]. Probiotics can be provided as a live microbial feed supplement, also known as direct-fed microbials (DFMs), in the poultry diet or water or can be administered to the developing embryo using in ovo feeding technology [11]. Probiotics and DFMs are interchangeably used for beneficial microbes by poultry scientists [12-16], though their functions and intent of use differ. Siragusa delineated the relationship between them as "Probiotics for livestock are termed direct-fed microbials or DFM" [17]. DFMs are beneficial microbe-containing feed additives that can complement the use of antibiotics 
and restore gut functions by stabilizing the gut microflora, enhancing animals' performance [18] and altering the rumen fermentation pattern in ruminants [19]. DFMs gained popularity because of their prophylactic efficacy against bacterial infections of the gut and immunomodulating activity [12]. DFMs function to normalize gut microbiota and prevent gut infection; in contrast, probiotics exert a broader array of benefits as functional foods [20] providing health gain and reducing the risk of diseases. Thus, although probiotics and DFMs have a different meaning, this review has used these terms interchangeably for practical application purposes, as those were reported by different workers.

The use of probiotics in poultry has increased steadily over the years due to the higher demand for antibiotic-free poultry and its well-researched benefits. The probiotic market reached 80 million USD in 2018, and this increasing trend of adding probiotics in poultry feed is expanding the global probiotics market, which is projected to reach 125 million USD by 2025 at a compound annual growth rate of $7.7 \%$ [21]. The benefits include enhanced growth and laying performance, improved gut histomorphology, immunity, and an increase in beneficial microbiota.

Each probiotic strain confers varying levels of protective efficacy, which is why many commercial products use multi-strain probiotics. Multiple-strain and multi-species probiotics act on different sites and provide different modes of action that create synergistic effects [22-24]. The genera of probiotic microorganisms commonly used for poultry include Bifidobacterium, Lactococcus, Lactobacillus, Bacillus, Streptococcus, and yeast such as Candida. The standard criteria for selecting probiotic strains include tolerance to gastrointestinal conditions, the ability to adhere to the gastrointestinal mucosa, and the competitive exclusion of pathogens $[9,22]$. Additionally, probiotics are selected based on their survival in manufacturing, transportation, storage, application processes, and their ability to maintain viability and desirable characteristics [4].

The mechanisms of action of probiotics are multifactorial and not fully characterized. Proposed mechanisms include the secretion of antimicrobial substances, competitive adherence to the mucosa and epithelium, the strengthening of the gut epithelial barrier, and the modulation of the immune system $[25,26]$. The benefits of probiotics may be potentiated by several methods, including strategic strain selection, gene manipulation, and the combination of synergistically acting components. A combinational approach is the most accepted practice in modern poultry production. This method uses both probiotics and prebiotics as synbiotics. Synbiotics are defined as a mixture of probiotics and prebiotics that beneficially affect the host by improving the survival and implantation of live microbial dietary supplements in the gastrointestinal tract [27]. Those effects are a result of activating the metabolism of one or more health-promoting bacteria or by selectively stimulating their growth, which improves the welfare of the host.

By analyzing the search results from the published manuscripts related to the potential use of probiotics in poultry, this review describes the potential of the 17 most commonly used probiotic species in increasing productivity and optimizing poultry performance and health under existing commercial production conditions. A comprehensive description of the mechanism of action, efficacy, advantages, and disadvantages are presented. Furthermore, potential strain selection and feeding strategies are discussed.

\section{Methodology}

The objective of this systematic review was to collect and critically discuss the information available on the use of probiotics in poultry and their effects on performance and gut health parameters. An electronic search was conducted using keywords germane to the topic to identify relevant studies. The publication characteristics, study design, study conduct and reporting, and study relevance were used as criteria for eligibility. An author index compiled all articles that met the inclusion and exclusion criteria. The keywords used for the search were: probiotics, direct-fed microbials, poultry feed, poultry supplementation, poultry nutrition, broiler chickens, poultry diet, growth performance, laying performance, immunology, gut histology, gut microbiota. The full-text articles published from 2000 to 2020 were combined from the search results and duplicates were removed. Information from 
each selected source was compiled while accounting for the strengths and weaknesses of each article. Studies that were weak in subject number or contained evident biases were considered but not contributive in summary.

By analyzing the methodologies of the articles, the most commonly used 17 probiotic species were critically assessed for their roles in nutrient utilization, growth performance, laying performance, gut histomorphology, immunity, and the modification of gut microbiota composition, and these probiotics are reviewed in this paper. Table 2 summarizes the main characteristics and notable effects of the selected 17 probiotic species in poultry.

Table 2. Summary of the beneficial probiotic species used in poultry production.

\begin{tabular}{|c|c|c|c|}
\hline Strain & Characteristics & Benefits & Reference \\
\hline Bacillus amyloliquefaciens & $\begin{array}{l}\text { Root-colonizing biocontrol bacteria used to } \\
\text { fight plant root pathogens in agriculture, } \\
\text { aquaculture, and hydroponics. }\end{array}$ & $\begin{array}{l}\text { Enhances gut health and growth } \\
\text { performance. }\end{array}$ & {$[16,28,29]$} \\
\hline Bacillus coagulans & $\begin{array}{l}\text { Bacteria exhibits the characteristics of both } \\
\text { genera Lactobacillus and Bacillus. }\end{array}$ & $\begin{array}{l}\text { Improve growth performance and gut } \\
\text { histomorphology. }\end{array}$ & [30] \\
\hline Bacillus licheniformis & Bacteria commonly found in soil. & $\begin{array}{l}\text { Prevents necrotic enteritis and enhances } \\
\text { growth performance. }\end{array}$ & {$[31]$} \\
\hline Bacillus subtilis & $\begin{array}{l}\text { Bacteria found in soil and the gastrointestinal } \\
\text { tract of ruminants and humans. }\end{array}$ & $\begin{array}{l}\text { Enhances laying performance and helps the } \\
\text { immune system and gut health. }\end{array}$ & {$[29,32-36]$} \\
\hline Bifidobacterium animalis & $\begin{array}{l}\text { Bacteria found in the large intestines of most } \\
\text { mammals. }\end{array}$ & $\begin{array}{l}\text { Helps the immune system, gut physiology, } \\
\text { and health. }\end{array}$ & {$[16,32]$} \\
\hline Bifidobacterium bifidum & $\begin{array}{l}\text { Bacteria that is one of the most common } \\
\text { probiotic bacteria that can be found in the } \\
\text { body of mammals. }\end{array}$ & Helps the immune system and gut health. & [11] \\
\hline Lactobacillus acidophilus & $\begin{array}{l}\text { Bacteria found in the human and animal } \\
\text { gastrointestinal tract and mouth. }\end{array}$ & $\begin{array}{l}\text { Enhances gut health and growth } \\
\text { performance. }\end{array}$ & {$[11,33,37,38]$} \\
\hline Lactobacillus bulgaricus & $\begin{array}{l}\text { Bacteria found in the gastrointestinal tract of } \\
\text { mammals and naturally fermented products. }\end{array}$ & $\begin{array}{c}\text { Enhances growth performance and improves } \\
\text { immune functions. }\end{array}$ & [31] \\
\hline Lactobacillus bifermentans & $\begin{array}{l}\text { Bacteria found in the human and animal } \\
\text { gastrointestinal tract. }\end{array}$ & $\begin{array}{l}\text { Enhances growth performance and digestive } \\
\text { health. }\end{array}$ & [39] \\
\hline Lactobacillus fermentum & $\begin{array}{l}\text { Bacteria found in fermenting animal and } \\
\text { plant material. }\end{array}$ & $\begin{array}{l}\text { Enhances growth performance, gut } \\
\text { histomorphology, and immune functions. }\end{array}$ & [39] \\
\hline Lactobacillus salivarius & $\begin{array}{l}\text { Bacteria found in the human and animal } \\
\text { gastrointestinal tract. }\end{array}$ & $\begin{array}{l}\text { Improves laying performance and enhances } \\
\text { gut histomorphology. }\end{array}$ & [40-42] \\
\hline $\begin{array}{l}\text { Lactobacillus } \\
\text { sanfranciscensis }\end{array}$ & $\begin{array}{l}\text { Heterofermentative bacteria closely related or } \\
\text { normally present in sourdough. }\end{array}$ & Enhances growth performance. & [39] \\
\hline Lactobacillus reuteri & $\begin{array}{l}\text { Bacteria that naturally inhabits the gut of } \\
\text { mammals and birds. }\end{array}$ & $\begin{array}{l}\text { Enhances growth performance, gut } \\
\text { histomorphology, immune system, and gut } \\
\text { health. }\end{array}$ & {$[16,39-41,43]$} \\
\hline Pediococcus acidilactici & $\begin{array}{l}\text { Bacteria found in fermented vegetables, } \\
\text { fermented dairy products, and meat. }\end{array}$ & $\begin{array}{l}\text { Improves laying performance and modulates } \\
\text { the gut microbiota. }\end{array}$ & [44-46] \\
\hline $\begin{array}{l}\text { Propionibacterium } \\
\text { acidipropionici }\end{array}$ & $\begin{array}{l}\text { Found in dairy products and the } \\
\text { environment. }\end{array}$ & $\begin{array}{l}\text { Contributes to the better development of gut } \\
\text { mucosa. }\end{array}$ & [47] \\
\hline Saccharomyces cerevisiae & $\begin{array}{l}\text { A species of yeast found primarily on ripe } \\
\text { fruits such as grapes. }\end{array}$ & $\begin{array}{l}\text { Enhances growth performance and improves } \\
\text { laying performance. }\end{array}$ & [48] \\
\hline Streptococcus faecium & $\begin{array}{l}\text { Bacteria inhabiting the gastrointestinal tracts } \\
\text { of humans and other mammals. }\end{array}$ & Improves immune functions. & {$[37,38]$} \\
\hline
\end{tabular}

\section{Nutrient Utilization}

Live microbes utilize nutrients and energy for their growth and proliferation within the host. Mountzouris et al. [44] investigated the effects of the inclusion level of five probiotic species (Lactobacillus reuteri DSM 16350, Enterococcus faecium DSM 16211, Bifidobacterium animalis DSM 16284, Pediococcus acidilactici DSM 16210, and Lactobacillus salivarius DSM 16351) in 525 male Cobb broilers. The study found that the higher inclusion level ( $10^{10}$ colony-forming unit (CFU) probiotic/kg of diet) of probiotic reduced the ileal digestibility and total tract apparent digestibility of nutrients compared to low-inclusion-level $\left(10^{8} \mathrm{CFU}\right.$ probiotic/kg of diet) probiotics. The authors explained the lower nutrient digestibility was due to the higher demand for nutrients by the probiotic microbes provided to the feed. The apparent metabolizable energy corrected for nitrogen $\left(\mathrm{AME}_{\mathrm{n}}\right)$ also did not differ significantly between different inclusion levels. 
B. subtilis DSM29784 resulted in a significant increase in nutrient retentions and dietary $A_{M} E_{n}$ in laying hens throughout the production cycle, where a total of 336 Shaver White layers were studied from 19 to 48 weeks of age [49]. Among the three inclusion levels (low, medium, and high), a high inclusion level of the bacteria increased the apparent retention of common nutrients, such as dry matter (DM), organic matter $(\mathrm{OM})$, crude protein $(\mathrm{CP})$, neutral detergent fiber (NDF), gross energy (GE), calcium, and total phosphorus, but the apparent metabolizable energy (AME) and AMEn were highest for the medium level of inclusion. Overall, the probiotics improved all these parameters when compared to the control fed no probiotic. This trend of improving the apparent total tract digestibility (ATTD) of $\mathrm{DM}, \mathrm{OM}, \mathrm{GE}$, and CP was also supported in a study by He et al. [50]. In this study, they investigated the effect of B. subtilis, B. licheniformis, and S. cerevisiae addition as probiotics in the feed of 168 Arbor Acres broilers. The results showed that probiotic supplementation improved the function of the intestinal barrier and increased the ratio of villus height to crypt depth, which led to a higher absorption in the intestine and a concurrent improvement in the ATTD of nutrients. B. subtilis, a spore-forming bacterial species, are partially effective, even in unsuitable farming conditions, in improving nutrient digestibility. When birds were challenged with the intramuscular inoculation of E. coli $(0.5 \mathrm{~mL}$ of culture containing $10^{8} \mathrm{CFU}$ of E. coli), the B. subtilis probiotic-fed birds showed a significantly higher digestibility of crude fiber, $\mathrm{CP}$, and GE [51]. The enhanced digestibility and absorption of nutrients may be attributed to the production of extracellular enzymes by the vegetative form of B. subtilis [52]. Jin et al. [53] investigated the effects of L. acidophilus and a mixture of 12 Lactobacillus strains (2 strains of L. acidophilus, 3 strains of L. fermentum, 1 strain of L. crispatus, and 6 strains of L. brevis) on the nutrient utilization in 180 day-old Arbor Acres chicks. Their result showed that both supplementations increased the levels of amylase in the small intestine and reduced the intestinal and fecal $\beta$-glucuronidase and fecal $\beta$-glucosidase activities at 40 days of feeding. Likewise, supplementation of Pediococcus acidilactici with or without a combination of mannan-oligosaccharides and butyric acid showed the ability to restore the amylase activity in Salmonella typhimurium-challenged broilers [54]. In a follow-up study [31], two other strains, B. licheniformis and L. bulgaricus, increased the ileal digestibility of amino acids, protein, and starch and the total tract digestibility of DM and OM. Recently, Singh et al. [55] evaluated the effects of a combination of enzymes with probiotics (3 Bacillus spp.) supplementation on the apparent ileal digestibility (AID) and ATTD of nutrients in Cobb 500 broilers. They found that the combination of enzymes and probiotics supplementation increased the AID of all amino acids except arginine and serine compared with the control. This finding suggests that probiotics influence the utilization of major nutrients selectively.

\section{Growth Performance}

Probiotics have been evaluated for their potential to improve growth performance in commercial poultry production since the phasing out of AGP in poultry feed. AGPs work by inhibiting the production and excretion of catabolic mediators by intestinal inflammatory cells, which, in turn, results in reduced intestinal microflora [56]. By contrast, probiotics promote growth by modulating the gut environment and enhancing gut barrier function via the fortification of beneficial intestinal microflora, the competitive exclusion of pathogens, and the stimulation of the immune system. After probiotics supplementation, non-pathogenic bacteria from probiotics compete with the pathogenic bacteria in gut for nutrients; colonize the intestine, leaving no space for harmful bacteria to occupy or establish; and secrete digestive enzymes (viz. $\beta$ galactosidase, $\alpha$ amylase, etc.), which helps in the increased absorption of nutrients and improves the growth performance of animals [57]. Thus, the mode of action for probiotics differs from that of antibiotics in birds. However, both could improve growth performance. Improvement in body weight gain (BWG) is commonly associated with an increased average daily feed intake (ADFI) and improved feed conversion ratio (FCR).

The improvement of BWG and FCR is the outcome of the use of probiotics, though the use of probiotics may not always improve the FCR. However, the average daily gain (ADG) may increase when there is an absence of significant improvement in FCR with probiotic supplementation. The treatment 
duration, concentration, and strain selection of the probiotics contribute to the outcomes as BWG, ADFI, and FCR. In the study of Awad et al. [40], the efficacy of L. salivarius and L. reuteri was evaluated using broiler chicks. The results showed that probiotics led to an improved body weight of broiler chicks at the finisher stage. Findings of Timmerman et al. [39] corroborated the results indicating higher productivity rates and ADG when 5000 day-old male Cobb 500 broiler chicks were used in the study. This study evaluated the effects of seven Lactobacillus strains as probiotics on the growth performance of broiler chickens: L. bifermentans W204.5, L. sanfranciscensis W205.6, L. sanfranciscensis W208.6, L. reuteri W218.2, L. reuteri W223.5, L. reuteri W227.3, and L. fermentum W227.5. Several other studies showed that multi-strain Lactobacillus supplements could be used as probiotics in commercial poultry production as they promote growth [58-60]. In a study by Ipek et al. [61], 720 one-day-old Cobb 500 broiler chicks were assigned into four treatment groups that were administered diets consisting of control and three groups of different measures of probiotics and prebiotics (PPS), which included live Saccharomyces cerevisiae strain. It was observed that, in all three groups of birds supplemented with PPS, the BWG was significantly higher than that of the control birds. Furthermore, a combination of multi-strain probiotics and xylanase enzyme was shown to work synergistically to increase the dietary energy uptake and hepatic energy retention [62]. The changes in energy may occur due to increased nutrient digestibility and enhanced FCR [62]. The changes in microbial populations in the gastrointestinal tract (GIT) caused by probiotics increase the production of short-chain fatty acids (SCFA) and cause immunomodulation, which improves energy metabolism as well [63]. When SCFA is produced through the microbial fermentation of carbohydrate in the intestine, the SCFA metabolites act on leukocytes and endothelial cells through activating G-protein-coupled receptors (GPCRs) and inhibit histone deacetylase. Besides the interaction with various receptors, SCFAs promote the generation of IgA by B-immune cells, inhibit the NF- $\kappa$ B transcription factor, and reduce chemokine and cytokine production [64]. Another study [65] compared the effects of feeding a mixture of DFM and a multienzyme combination (xylanase, amylase, and protease) as AGP in the feed with the same multienzyme combination alone. The results showed that probiotic Bacillus strains as a DFM could be an alternative to AGP considering the enhanced feed intake, feed efficiency, and BWG in probiotic-fed broilers [65]. This improvement in feed efficiency may be due to the reduced pathogen load in the gut, the enzymatic degradation of the antinutritive factors, a reduction in the viscosity of the digesta, and the development of a congenial environment for the beneficial gut microbes [66]. Another study of He et al. [50] suggested that a multi-species probiotic (Bacillus subtilis, B. licheniformis, and Saccharomyces cerevisiae) could improve the growth performance and could be a substitute for chlortetracycline, one of the AGPs.

The supplementation of different probiotic species may perform differently with varied results. A comparative study showed that B. licheniformis and B. subtilis, both as probiotics, improved BWG, FCR, and production efficiency factor (PEF). However, the former species outperformed the later in improving BWG and PEF [67]. On the contrary, studies [13,36,47] showed no effect of probiotics supplementation on broiler growth performance. When 294 day-old Cobb broiler chickens were used to investigate the effects of four Lactobacillus strains (L. johnsonii, L. crispatus, L. salivarius and an unidentified Lactobacillus sp.) on the gut microbial profile and growth performance, probiotic supplementation did not significantly improve BWG, ADFI, and FCR [42]. Similarly, the study of Fathi et al. [36] found no beneficial effects of probiotic supplementation on the growth performance of broilers at high-heat conditions. In addition to growth performance, Bai et al. [35] evaluated the effects of $B$. subtilis on intestinal immune characteristics. The results indicated positive effects on the intestinal T-cell immune system. Similarly, Propionibacterium acidipropionici produced no differences in feed intake and bodyweight, though it produced expected histomorphological changes in the gut [47].

Zhen et al. [30] found that Bacillus coagulans, when supplemented in cobb broilers challenged with Salmonella enteritidis, increased the BWG and FCR on day 15 to day 21 compared to non-supplemented birds. Unlike other studies, one study showed negative or no effects of probiotic supplementation on the gut microbiome of poultry [68]. However, in this study, probiotic-treated birds were placed under heat stress, which may have influenced the outcome. The experiment used 450 broiler chicks to 
investigate the effects of mannan oligosaccharide and probiotics on growth performance, the relative weights of viscera, and the population of selected intestinal bacteria in cyclic heat-stressed broilers.

\section{Laying Performance}

In poultry production, several strategies are used to increase the number of eggs laid, increase the egg weight, and improve the egg quality. The inclusion of probiotics into the diets of laying hens improves laying production by increasing daily feed consumption, increasing nitrogen and calcium retentions, and decreasing intestinal length. It has been proposed that probiotics increase the intestinal fermentation rate and production of SCFA, which provide nourishment for intestinal epithelial cells, which, in turn, leads to improved mineral assimilation [37]. Egg quality typically encompasses several aspects, such as shell weight and albumen and yolk quality. Egg quality has a genetic basis and varies between strains of laying hens. However, the egg quality is also influenced by the housing regimen under which the hens are kept, the age of the laying hens, and the feed used.

Studies found that probiotic supplementation has effects on egg production $[29,33,34,45,69]$. The following variables were considered to evaluate egg production performance: ADFI, ADG, FCR, the number of the eggs laid, egg weight, specific gravity, serum and egg yolk cholesterol, and serum triglyceride. A recent study [34] investigated the effects of commercial multi-strain probiotics on production performance and egg quality characteristics. The results showed that supplementation increased some parameters related to egg production, such as egg weight and size, albumin and yolk weight, and the eggshell thickness and strength, when compared to the control group.

Pan et al. [69] conducted a 35-day experiment to evaluate the effects of selenium-enriched probiotics (SP) on laying performance, egg quality, egg selenium (Se) content, and egg glutathione peroxidase (GPX) activity. A total of 500 Rohman laying hens at the age of 58 weeks were randomly allocated to one of five dietary treatments. The SP supplementation increased the rate of egg laying, day egg weight, mean egg weight, egg Se content, and egg GPX activity. It simultaneously decreased the feed to egg ratio and egg cholesterol content. These results suggested that the Se contents and GPX activity of eggs were affected by the dietary Se level. In contrast, the egg-laying performance and egg cholesterol content were affected by the probiotic supplementation. It was concluded that this SP is an effective supplement for increasing the production performance of laying hens.

A study by Mazanko et al. [29] sought to elucidate the effects of Bacilli probiotic preparations on the physiology of laying hens and roosters. Probiotic formulations were prepared as soybean products fermented by B. subtilis KATMIRA1933 and B. amyloliquefaciens B-1895. In this study, both strains improved the laying performance, egg quality, and sperm quality of roosters. Considering the cost-effectiveness of the soy-based probiotic preparations, these supplements showed promising results for modern poultry production.

In addition to soy-based probiotic preparations, distiller-dried grains with solubles (DDGS) is widely used as an alternative feedstuff in poultry diets. The DDGS is not only a source of nutrients but can also provide some functional benefits to animals due to their high fiber content. In the study of Abd El-Hack et al. [34], Bacillus subtilis was used to evaluate the impacts of the graded level of DDGS and probiotic on performance, egg quality, blood metabolites, and nitrogen and phosphorus excretion in the manure. A total of 216 Hi-sex Brown laying hens of 22 weeks of age were randomly divided into eight treatment groups and fed with four levels of DDGS and two levels of $B$. subtilis probiotics. The results showed improved ADFI, egg shape index, and yolk color in the probiotic-supplemented birds compared to the control. The inclusion of $B$. subtilis probiotic enhanced the overall feed efficiency, egg weight, and egg mass. Neijat et al. [49] also showed that the inclusion of B. subtilis improved the albumen height and Haught unit of the eggs throughout the production cycle from 19 to 48 weeks of age. The lowest shell breaking strength found at week 20 was a drawback of the high supplementation of the probiotic. Except for age difference, no treatment effect was evident on the shell thickness and shell breaking strength. Xiang et al. [70] also evaluated the use of probiotics containing C. butyricum and a combination of S. boulardii and P. acidilactici in laying performance. They found that dietary 
C. butyricum supplementation significantly affected the performance of laying hens and improved the gut morphology.

\section{Gut Histomorphology}

Intestinal morphological measurements, such as increased villus height, short crypt depth, higher villus height-crypt depth ratio, etc., indicate an increase in nutrient absorption by increasing the available surface area for nutrient absorption. Likewise, the number of goblet cells in the intestinal villi and crypts is another health indicator of the intestine, as these cells produce mucin and exclude harmful pathogens from adhesion to the intestinal epithelium [71]. Different probiotic strains have been studied for their influence on those gut histomorphological features. Elucidating the histological and morphological indexes of the intestinal mucosa of broilers is vital in determining the strain characteristics and modes of action. Probiotics inclusion in feed has been found to change the gut histomorphology, though the degree of changes varied from strain to strain. Alagawany et al. [38] reported that a probiotic containing L. casei, L. acidophilus, Bifidobacterium thermophilum, and Enterococcus faecium increased the jejunal villus height and decreased the villus crypt depth. Longer villi indicate an improvement in feed efficiency and growth-promoting efficiency. These results were corroborated by Jin et al. [53] when they investigated the effects of L. acidophilus and a mixture of 12 Lactobacillus strains on the organ weight and intestinal microbiota of 180 day-old Arbor Acres chicks. The supplementation of L. salivarius and L. reuteri [41]; Pediococcus acidilactici [54]; a mixture of L. casei, L. acidophilus, Bifidobacterium thermophilum, and Enterococcus faecium [38]; a mixture of Bacillus subtilis, B. licheniformis, and Saccharomyces cerevisiae [50]; B. coagulans [30]; and Propionibacterium acidipropionici [47] were assessed in broiler chickens to observe the histomorphological changes caused by the use of probiotics. These studies showed a positive influence on the histomorphological measurements of the small intestinal villi, with an increase in the villus height and villus height to crypt depth ratio. This result suggested that the addition of $L$. salivarius and $L$. reuteri can enhance the intestinal nutrient absorption and intestinal architecture.

The intestinal epithelium selectively allows nutrient absorption but prevents the entrance of pathogens into the bloodstream [72]. Lactobacillus plantarum and L. reuteri, when supplemented with feed to broilers, increased that type of barrier integrity and suppressed the entry of certain opportunistic or pathogenic bacteria [73].

In a study [30] where broilers were challenged with Salmonella enteritidis (SE), the results showed a significant reduction in goblet cell numbers at day 7 post-infection (DPI), a decreased villus height. and villus-crypt ratio in the small intestine. In contrast, the chickens receiving Bacillus coagulans diets showed improvement, with a lower crypt depth and the higher villus-crypt ratio at 17 DPI and an increase in the goblet cell count at 7 and 17 DPI in the jejunum. Intestinal goblet cells produce mucin2, a component of mucus, that helped to restore the barrier function in SE-challenged chickens.

Another study [74] showed that a probiotic mixture of B, licheniformis, B. subtilis, and L. plantarum is capable of ameliorating the heat-stress induced impairment of gut microflora, histomorphology, and barrier integrity in broilers. This supplementation altered and increased the number of small intestinal Lactobacilli and Bifidobacterium and increased the jejunal villus height. The broilers benefited from a decreased feed to gain ratio and a reduced load of small intestinal coliforms.

Forte et al. [33] experimented on 180 Hy-Line hybrids of 16-week-old laying hens. They administered dietary L. acidophilus and B. subtilis and evaluated the effects on the microflora, morphology, and morphometry of the gut. The result did not show substantial differences among the different groups and treatments in the morphological and morphometric changes.

Several other multi-strain probiotics have been assessed recently. Wealleans et al. [75] evaluated the effects of avilamycin (as AGP) and multi-strain Bacillus probiotics on the growth performance, gut histomorphometry, and microbiota of broilers fed on a mixed-grain diet. In that study, 800 chicks were allocated to one of four treatments (control, control+AGP, control+DFM, or control+AGP+DFM). Growth performance indicators (BWG, ADFI, and FCR) were measured, and on day 42 the villus height 
and crypt depth were determined. The results showed that the AGP+DFM group had significantly increased body weight, villus height, and crypt depth compared to the control. Additionally, there was a notable reduction in the E. coli counts and increased Lactobacilli counts as compared to the control.

Propionibacterium acidipropionici supplementation increased the SCFA concentration at day 14 and that higher concentration was sustained until the end of the trial. It helped in the better development of the gut mucosa, which was evidenced by an increase in the length of the villus-crypt units, goblet cell counts, and neutral mucin production [47].

\section{Immunity}

Pathogens must overcome numerous obstacles to colonize the intestinal tract and cause an infection. Physical restraints such as low gastric $\mathrm{pH}$ and rapid transit time in the small intestine play an essential role. Additionally, pathogens must overcome the inhibitory effects of the gut microbiota, the physical barrier of the epithelium, and the response of the host immune system to successfully strike an infection. Recent publications demonstrate that certain species of non-pathogenic intestinal microbiota communicate with the epithelium and immune system, modulating the tissue physiology and the ability to respond to infection. The modulation of intestinal environments is considered a significant effect of probiotics and is regarded as the basis of other probiotic benefits. The epithelial cells and dendritic cells of the intestine act as mucosal sentinel cells in the gut-associated lymphoid tissue. The microbe-associated molecular patterns of probiotics, when bound to the Toll-like receptors of sentinel cells, activate the NF-KB and MAP kinase pathways [25]. This activation causes the upregulation or suppression of genes that regulate the inflammatory response, as well as cytoprotective effects through immune activation, antigen presentation, and the expression of antimicrobial factors [76]. Additionally, the benefits include an increased epithelial barrier, the increased adhesion of beneficial bacteria to the intestinal mucosa, and the concomitant inhibition of pathogen adhesion [26].

The effectiveness of probiotic supplementation in reducing the amount and severity of enteric diseases in poultry has been widely studied in recent years. As the gut microbiota establishes after the chick hatches, an earlier introduction to non-pathogenic microorganisms can enhance the digestive tract. It is essential to define the conditions under which they show efficacy and determine the mechanisms of action for the effective use of probiotics in the future.

The immune responses of probiotic supplementation in broiler chickens vary by strain. Generally, probiotics are used to help maintain a healthy microbial balance within the intestine to promote gut integrity and immune health. Probiotic bacteria can induce beneficial effects by producing antimicrobial substances such as SCFA and bacteriocins that limit the growth and survival of pathogenic microbes [77]. Notably, several strains of Lactobacillus have been found to lower the environmental $\mathrm{pH}$ through the production of lactic acid. Probiotics supplementation can modify immunity in poultry [11,28,32,78-80]. In the study of Li et al. [28], 192 day-old male Arbor Acre broiler chickens were used to evaluate the immune functions and their response. The results showed that B. amyloliquefaciens alleviates immunological stress in lipopolysaccharide-challenged broilers at an early age. In addition, supplementation increased the lysozyme activity in plasma and increased the white blood cell count. Li et al. [28] concluded that B. amyloliquefaciens could partially alleviate the compromised growth performance and immune status of broilers under immune stress at an early age.

Combined L. acidophilus, L. casei, S. faecium, and B. subtilis were studied for their effects on the immunity of poultry. In a study of Yitbarek et al. [80], 300 day-old Lohmann chicken pullets were fed multi-strain probiotics along with bacitracin methylene disalicylate and yeast-derived carbohydrates. The supplementation provided immune modulation. In the ileum, the synbiotics supplementation resulted in the upregulation of IL-6, interferon (IFN)- $\gamma$, and IL-4. This showed that the synbiotics provided a more pronounced immune modulation, maintaining immune homeostasis and oral tolerance, which was observed in a robust IL-10 response.

Common probiotics such as B. animalis, B. bifidum, L. reuteri, L. acidophilus, S. faecalis, and B. subtilis can produce immune responses in poultry [11,16,32]. Although the probiotic supplementation 
developed positive immune responses, Sadeghi et al. [32] observed that environmental conditions played an important role in determining the strain efficacy. Sadeghi's study investigated the effects of B. subtilis on antibody titers against Newcastle and infectious bursal viruses in 160 broiler chickens challenged with Salmonella enterica serotype Enteritidis. The results showed that B. subtilis had no significant effects on the immune parameters of chickens in non-contaminated environments but displayed an excellent efficacy at the environment contaminated with pathogens. Similar results were found in the study of Teo and Tan [81]. A probiotic containing B. subtilis improved the feed conversion and intestinal morphology; enhanced the immune response; and inhibited the gastrointestinal tract colonization by C. jejuni, Escherichia coli, and Salmonella Minnesota.

When a multi-strain lactobacillus probiotic culture (3 Lactobacillus bulgaricus, 3 Lactobacillus fermentum, 2 Lactobacillus casei, 2 Lactobacillus cellobiosus, and 1 Lactobacillus helveticus) was administered in SE-challenged broilers, the probiotics reduced the number of macrophages in the ileum and caeca [82]. The reduction in macrophage count for the infected birds could be attributed to a decrease in the bacterial load due to competitive exclusion via the addition of probiotics.

Probiotic bacteria also contribute to intestinal barrier integrity by modulating mucin production. Mucins are the primary protein component coating the GIT. Probiotics normalize intestinal integrity through the restoration of the mucus layer by adjusting the mucin monosaccharide composition, mucus layer thickness, and mucin gene expression [83]. The structural and functional properties of mucins influence bacterial adhesion to the mucosal surface. In broilers, probiotics modulate intestinal mucin monosaccharide compositions, subsequently altering the GIT microbiota composition. In addition to supplementing via feed or water, probiotics have also been fed in ovo. In the in ovo feeding technique, supplements are injected to the incubating eggs to modulate the development of healthy birds and improved gut health, thereby improving the performance of chickens, which lasts from preto post-hatch to adult age [84]. When Pender et al. [11] evaluated the effects of the in ovo inoculation of S. faecalis and L. acidophilus, both strains were found to act as immunomodulators, as evidenced by the effect on the expression of several immune-related genes within the ileum and cecal tonsils. The results showed an initial upregulation of inducible nitric oxide synthase on the day of the hatch (3 days post-inoculation). In ovo probiotic supplementation was associated with downregulated expression of innate immunity markers Toll-like receptor-2 and 4, inducible nitric oxide synthase (iNOS), trefoil factor-2 (TFF-2), and mucin-2 (Muc-2). However, there were different expression patterns at various time points $(4,6,8,15$, and 22 days of age).

Oakley and Kogut [85] reported that the succession of changes in the gut microbiota correlates with changes in the cytokine profile expressed by host intestinal cells in response to different bacterial groups. According to their findings, the higher the relative abundance of various members of the phylum Firmicutes (such as Bacillus, Listeria, Staphylococcus, Streptococcus, Lactobacillus etc.), the lower the transcription of pro-inflammatory cytokines; and the relationship is inverse for the Proteobacteria (such as Escherichia, Salmonella, Shigella, Brucella etc.).

A study [86] on 10-week-old rearing hens suggested that L. salivarius expressing 3D8 scFv can be a potential candidate as a probiotic as it prevents activation of the immune system and maintains immune homeostasis. The oral administration of $L$. salivarius/3D8 significantly reduced the IL-8, TNF- $\alpha$, IL-4, IL-1 $\beta$, IFN- $\gamma$, and IGFq expression with this supplementation when the results were compared to the control of the wild-type L. salivarius-treated group of hens. In conclusion, the differences in results in the six studies could be due to various factors that can alter the effects such as the strain type, composition and viability, and preparation methods. Other factors include the dosage, frequency of application, overall diet, condition and age of the birds, potential drug interactions, and environmental stress factors such as temperature and stocking density.

\section{Gut Microbiota}

Diverse gut microbiota plays a significant role in host metabolism, growth performance, nutrient digestion, and overall health of birds [8]. The composition of chicken gut microbiota depends on 
age, especially at the early stages of life, genotype, farming conditions/environment, and diet/feed additives [87]. Sometimes, the gut microbiota composition can be altered severely by non-infectious or infectious stressors. Consequently, this dysbiosis can impact intestinal morphology and activities (e.g., increased permeability of the intestine, higher risk of bacterial infection, sepsis, inflammation, and reduced digestion) [88].

Probiotics can affect the health, performance, and disease risk of the hosts, as they can amend the dysbiosis and improve the balance of gut microbiota in healthy hosts by reducing the proliferation of pathogenic species and increasing the beneficial bacteria $[4,8]$. The most commonly used probiotic species belong to the genera Lactobacillus, Streptococcus, Bacillus, Bifidobacterium, Enterococcus, Aspergillus, Candida, and Saccharomyces [80] and exert preferential health benefits on the host through the competitive exclusion of deleterious bacteria and the immune modulation in the gut [4]. Several studies have found effects of probiotics supplementation on the gut microbiota, enzyme activities, and microbial fermentation in the digestive tract in broiler chickens [43,47,78,80,89-91].

Mountzouris et al. [92] assessed the effects of a multi-bacterial species probiotic, which contained 2 Lactobacillus strains, 1 Bifidobacterium strain, 1 Enterococcus strain, and 1 Pediococcus strain. Four hundred day-old male Cobb broilers were allocated to four experimental treatments for six weeks of study. The bodyweight, ADFI, and FCR were determined weekly, and cecal microflora composition, the concentration of SCFA, and activities of 5 bacterial glycolytic enzymes ( $\alpha$-galactosidase, $\beta$-galactosidase, $\alpha$-glucosidase, $\beta$-glucosidase, and $\beta$-glucuronidase) were determined at the end of the study. The results showed that probiotic treatment had significantly higher specific activities of $\alpha$-galactosidase and $\beta$-galactosidase than the control birds. Overall, the probiotic treatment displayed a growth-promoting effect that was comparable to avilamycin (an AGP) treatment. It suggests that probiotics modulate the composition and activities of the cecal microflora of broiler chickens.

Since newly hatched broiler chickens demonstrate a delayed commensal colonization and low bacterial diversity, they are ideal for controlling development and studying the composition of the intestinal microbiota. Nakphaichit et al. [43] evaluated the role of L. reuteri in newly hatched broiler chicks for the first-week post-hatch. The growth performance and ileum microbiota of the chickens were monitored for six weeks. The results showed the number of total bacteria in ileum samples at d 42 was five times higher in the probiotic group than in the control group. Four additional strains were analyzed in another study with 294 day-old Cobb broiler chickens [42]: L. johnsonii, L. crispatus, L. salivarius, and one unidentified Lactobacillus spp. The microbial profile and production performance were evaluated. The results showed that the addition of probiotic Lactobacillus spp. to feed increased the number of total anaerobic bacteria in the ileum and ceca, and the number of lactic acid bacteria and Lactobacilli in the ceca. Furthermore, all four probiotics tended to reduce the number of Enterobacteria in the ileum compared with the control treatments. An important feature of Lactobacilli is the ability to auto- and co-aggregate. Typically, bacteria demonstrating a high auto-aggregation capacity show a good adhesion to the mucus.

Martínez et al. [47] studied the probiotic potential of Propionibacterium acidipropionici. P. acidipropionici LET105 and LET107 were administered at a concentration of $106 \mathrm{cfu} / \mathrm{mL}$ in the drinking water. This supplementation showed the normal development of lactic acid bacteria and Bifidobacteria but a slow colonization by Bacteroides. Eventually, this increased the lactic acid production and lowered butyric acid production with a rise in mucus secretion, which increased the protection against pathogens.

The probiotic supplementation of broilers with B. licheniformis and B. subtilis did not show a significant effect on the ileal and cecal microflora [67]. This non-significant effect on total aerobic and Salmonella count in the gut was also found when a mash diet supplemented with Lactobacillus acidophilus, L. casei, Enterococcus faecium, and Bifidobacterium thermophilus was fed to Ross 308 broiler chickens [93].

L. salivarius expressing 3D8 scFv has been found as beneficial in the study [86], where it showed the supplementation of that strain increased the abundance of Firmicutes, Proteobacteria, Actinobacterias, and Bacteroides in the fecal samples. Considering the abundance at the genus level, Lactobacillus was 
found as the most abundant genus, constituting $22.8 \%$ of the microbiota in the fecal samples in the L. salivarius 3D8 scFv treated chickens. A combination of L. salivarius and Pediococcus parvulus also improved the weight gain, intestinal morphology, and immune response [94]. Neveling and co-authors have shown that a combination of Lactobacillus crispatus, L. salivarius, L. gallinarum, L. johnsonii, Enterococcus faecalis, and Bacillus amyloliquefaciens inhibited the colonization of Salmonella in the GIT of broilers. Broilers treated with the multi-species probiotic had higher levels of lysozyme in their serum and higher T lymphocyte responses compared to control birds.

Probiotics favor the growth of bacteria of specific genera. When broilers challenged with Salmonella enteritidis were fed with a Bacillus coagulans-containing diet, this diet helped increase the Lactobacilli and Bifidobacterium but lowered the coliform and salmonella concentration in the cecum [30]. Besides that, this reduced the salmonella loads in the liver of the chickens.

The probiotic bacteria can initiate gene exchange with the gut microbiome and transfer genetic attributes to the surrounding bacteria. Their intimate cell-to-cell contact with other bacterial inhabitants of intestinal ecosystem increases the odds of genetic exchange of plasmids [95]. This conjugation process transfers the genes responsible for the acquired resistance of the probiotic microbe against antibiotics to the natural commensal microbes of the gut [96]. Studies related to human probiotics have identified different antibiotic resistance determinants in the genome of probiotic species of the Lactobacillus, Bifidobacterium, and Bacillus genera which have potential to transfer genetic resistance genes to other bacteria $[97,98]$. However, enough concern has not been observed about antibiotic resistance gene transfer in poultry through probiotic supplementation.

\section{Conclusions}

Probiotics are considered a captivating feed additive because of their immense empirical benefits: improvement in the gut microbiological homeostasis, immune response, growth, and laying performances. The use of probiotics in poultry production may address the public health concerns of antimicrobial resistance development to some extent, as this could replace the use of some subtherapeutic antibiotics. Studies showed a range of variation in the incurred benefits because of the differences in the methodologies of the experiments (e.g., the strains of probiotics, the dose of probiotics, the age, the breed of birds, the species, the inoculation level of challenging pathogens, and external factors). Many studies have attempted to compare the benefits among different inclusion levels of probiotics. However, no conclusive recommendation can be made regarding the optimal dose of probiotics, as the reported investigations were conducted under conditions with various confounding factors-e.g., variations in diet, husbandry, and stressors. Though the benefits are evident in different studies, details about probiotics' mechanisms of action are yet to be unraveled. Future studies should be directed to find the mechanism of action of probiotics, determine the optimal dose for single- or multi-strain probiotics, measure the effect in birds with flaws in gut integrity and enteric diseases, eliminate the risks of antibiotic resistance gene transfer, and set selection criteria for new probiotic species. Some human studies have shown that probiotic supplementation may incur some health risks. Similar studies in poultry are necessary to find the negative consequences of probiotic use as well.

Author Contributions: R.D., S.O., and P.M. reviewed the literature and drafted the manuscript; R.J. conceptualized, wrote, and reviewed the manuscript. All authors have read and agreed to the published version of the manuscript.

Funding: This work was supported by the USDA National Institute for Food and Agriculture, Hatch-Multistate fund, managed by the College of Tropical Agriculture and Human Resources, University of Hawaii at Manoa, Honolulu, HI, USA.

Conflicts of Interest: The authors declare no conflict of interest. 


\section{References}

1. European Commission. Ban on Antibiotics as Growth Promoters in Animal Feed Enters into Effect; Press Release Database. European Commision: Brussels, Belgium, 2005. Available online: http://europa.eu/rapid/pressrelease_IP-05-1687_en.htm (accessed on 2 October 2020).

2. Roth, N.; Käsbohrer, A.; Mayrhofer, S.; Zitz, U.; Hofacre, C.; Domig, K.J. The application of antibiotics in broiler production and the resulting antibiotic resistance in Escherichia coli: A global overview. Poult. Sci. 2019, 98, 1791-1804. [CrossRef]

3. Jha, R.; Berrocoso, J.D. Review: Dietary fiber utilization and its effects on physiological functions and gut health of swine. Animal 2015, 9, 1441-1452. [CrossRef]

4. Bajagai, Y.S.; Klieve, A.V.; Dart, P.J.; Bryden, W.L. Animal Production and Health Div Probiotics. In Animal Nutrition: Production, Impact and Regulation; Food and Agriculture Organization of the United Nations: Rome, Italy, 2016; ISBN 978-92-5-109333-7.

5. Jha, R.; Fouhse, J.M.; Tiwari, U.P.; Li, L.; Willing, B.P. Dietary Fiber and Intestinal Health of Monogastric Animals. Front. Vet. Sci. 2019, 6, 48. [CrossRef]

6. Cervantes, H. Antibiotic-free poultry production: Is it sustainable? J. Appl. Poult. Res. 2015, 24, 91-97. [CrossRef]

7. Adhikari, P.; Kiess, A.; Adhikari, R.; Jha, R. An approach to alternative strategies to control avian coccidiosis and necrotic enteritis. J. Appl. Poult. Res. 2020, 29, 515-534. [CrossRef]

8. Yadav, S.; Jha, R. Strategies to modulate the intestinal microbiota and their effects on nutrient utilization, performance, and health of poultry. J. Anim. Sci. Biotechnol. 2019, 10, 2. [CrossRef]

9. Gadde, U.D.; Kim, W.H.; Oh, S.T.; Lillehoj, H.S. Alternatives to antibiotics for maximizing growth performance and feed efficiency in poultry: A review. Anim. Health Res. Rev. 2017, 18, 26-45. [CrossRef]

10. Probiotics in Food: Health and Nutritional Properties and Guidelines for Evaluation; FAO Food and Nutrition Paper; Food and Agriculture Organization of the United Nations: Rome, Italy; World Health Organization: Geneva, Switzerland, 2006; ISBN 978-92-5-105513-7.

11. Pender, C.M.; Kim, S.; Potter, T.D.; Ritzi, M.M.; Young, M.; Dalloul, R.A. In ovo supplementation of probiotics and its effects on performance and immune-related gene expression in broiler chicks. Poult. Sci. 2017, 96, 1052-1062. [CrossRef]

12. Lee, K.-W.; Lillehoj, H.S. An update on direct-fed microbials in broiler chickens in post-antibiotic era. Anim. Prod. Sci. 2017, 57, 1575. [CrossRef]

13. Gadde, U.D.; Oh, S.; Lee, Y.; Davis, E.; Zimmerman, N.; Rehberger, T.; Lillehoj, H.S. Dietary Bacillus subtilisbased direct-fed microbials alleviate LPS-induced intestinal immunological stress and improve intestinal barrier gene expression in commercial broiler chickens. Res. Vet. Sci. 2017, 114, 236-243. [CrossRef]

14. Tellez, G.; Pixley, C.; Wolfenden, R.E.; Layton, S.L.; Hargis, B.M. Probiotics/direct fed microbials for Salmonella control in poultry. Food Res. Int. 2012, 45, 628-633. [CrossRef]

15. Hernandez-Patlan, D.; Solis-Cruz, B.; Pontin, K.P.; Hernandez-Velasco, X.; Merino-Guzman, R.; Adhikari, B.; López-Arellano, R.; Kwon, Y.M.; Hargis, B.M.; Arreguin-Nava, M.A.; et al. Impact of a Bacillus Direct-Fed Microbial on Growth Performance, Intestinal Barrier Integrity, Necrotic Enteritis Lesions, and Ileal Microbiota in Broiler Chickens Using a Laboratory Challenge Model. Front. Vet. Sci. 2019, 6, 108. [CrossRef]

16. Ahmed, S.T.; Islam, M.M.; Mun, H.-S.; Sim, H.-J.; Kim, Y.-J.; Yang, C.-J. Effects of Bacillus amyloliquefaciens as a probiotic strain on growth performance, cecal microflora, and fecal noxious gas emissions of broiler chickens. Poult. Sci. 2014, 93, 1963-1971. [CrossRef]

17. Siragusa, G. Modern Probiology_Direct Fed Microbials and the Avian Gut Microbiota. In Proceedings of the 23rd Annual Australian Poultry Science Symposium, Sydney, NSW, Australia, 19-22 February 2012.

18. Bernardeau, M.; Vernoux, J.-P. Overview of differences between microbial feed additives and probiotics for food regarding regulation, growth promotion effects and health properties and consequences for extrapolation of farm animal results to humans. Clin. Microbiol. Infect. 2013, 19, 321-330. [CrossRef]

19. Raeth-Knight, M.L.; Linn, J.G.; Jung, H.G. Effect of Direct-Fed Microbials on Performance, Diet Digestibility, and Rumen Characteristics of Holstein Dairy Cows. J. Dairy Sci. 2007, 90, 1802-1809. [CrossRef] 
20. Roberfroid, M.B. Global view on functional foods: European perspectives. Br. J. Nutr. 2002, 88, S133-S138. [CrossRef]

21. Ahuja, K.; Mamtani, K. Poultry Probiotic Ingredients Market Size by Product (Lactobacilli, Bifidobacterium, Streptococcus, Bacillus), by Application (Broilers, Layers, Turkeys, Breeders, Chicks \& Poults), Regional Outlook, Application Potential, Price Trends, Competitive Market Share \& Forecast, 2019-2025. 2019. Available online: https://www.gminsights.com/industry-analysis/poultry-probiotics-market (accessed on 2 October 2020).

22. Klaenhammer, T. Selection and design of probiotics. Int. J. Food Microbiol. 1999, 50, 45-57. [CrossRef]

23. Timmerman, H.M.; Koning, C.J.M.; Mulder, L.; Rombouts, F.M.; Beynen, A.C. Monostrain, multistrain and multispecies probiotics-A comparison of functionality and efficacy. Int. J. Food Microbiol. 2004, 96, 219-233. [CrossRef]

24. Kazemi, S.A.; Ahmadi, H.; Karimi Torshizi, M.A. Evaluating two multistrain probiotics on growth performance, intestinal morphology, lipid oxidation and ileal microflora in chickens. J. Anim. Physiol. Anim. Nutr. 2019, 103, 1399-1407. [CrossRef]

25. Bai, S.P.; Wu, A.M.; Ding, X.M.; Lei, Y.; Bai, J.; Zhang, K.Y.; Chio, J.S. Effects of probiotic-supplemented diets on growth performance and intestinal immune characteristics of broiler chickens. Poult. Sci. 2013, 92, 663-670. [CrossRef]

26. Broom, L.J.; Kogut, M.H. Gut immunity: Its development and reasons and opportunities for modulation in monogastric production animals. Anim. Health Res. Rev. 2018, 19, 46-52. [CrossRef]

27. Alizadeh, M.; Munyaka, P.; Yitbarek, A.; Echeverry, H.; Rodriguez-Lecompte, J.C. Maternal antibody decay and antibody-mediated immune responses in chicken pullets fed prebiotics and synbiotics. Poult. Sci. 2017, 96, 58-64. [CrossRef]

28. Li, Y.; Zhang, H.; Chen, Y.P.; Yang, M.X.; Zhang, L.L.; Lu, Z.X.; Zhou, Y.M.; Wang, T. Bacillus amyloliquefaciens supplementation alleviates immunological stress in lipopolysaccharide-challenged broilers at early age. Poult. Sci. 2015, 94, 1504-1511. [CrossRef]

29. Mazanko, M.S.; Gorlov, I.F.; Prazdnova, E.V.; Makarenko, M.S.; Usatov, A.V.; Bren, A.B.; Chistyakov, V.A.; Tutelyan, A.V.; Komarova, Z.B.; Mosolova, N.I.; et al. Bacillus Probiotic Supplementations Improve Laying Performance, Egg Quality, Hatching of Laying Hens, and Sperm Quality of Roosters. Probiotics Antimicrob. Proteins 2018, 10, 367-373. [CrossRef]

30. Zhen, W.; Shao, Y.; Gong, X.; Wu, Y.; Geng, Y.; Wang, Z.; Guo, Y. Effect of dietary Bacillus coagulans supplementation on growth performance and immune responses of broiler chickens challenged by Salmonella enteritidis. Poult. Sci. 2018, 97, 2654-2666. [CrossRef]

31. Cheng, Y.; Chen, Y.; Li, X.; Yang, W.; Wen, C.; Kang, Y.; Wang, A.; Zhou, Y. Effects of synbiotic supplementation on growth performance, carcass characteristics, meat quality and muscular antioxidant capacity and mineral contents in broilers: Effects of synbiotic supplementation. J. Sci. Food Agric. 2017, 97, 3699-3705. [CrossRef]

32. Sadeghi, A.; Toghyani, M.; Gheisari, A. Effect of various fiber types and choice feeding of fiber on performance, gut development, humoral immunity, and fiber preference in broiler chicks. Poult. Sci. 2015, 94, 2734-2743. [CrossRef]

33. Forte, C.; Acuti, G.; Manuali, E.; Casagrande Proietti, P.; Pavone, S.; Trabalza-Marinucci, M.; Moscati, L.; Onofri, A.; Lorenzetti, C.; Franciosini, M.P. Effects of two different probiotics on microflora, morphology, and morphometry of gut in organic laying hens. Poult. Sci. 2016, 95, 2528-2535. [CrossRef]

34. Abd El-Hack, M.E.; Mahgoub, S.A.; Alagawany, M.; Ashour, E.A. Improving productive performance and mitigating harmful emissions from laying hen excreta via feeding on graded levels of corn DDGS with or without Bacillus subtilis probiotic. J. Anim. Physiol. Anim. Nutr. 2017, 101, 904-913. [CrossRef]

35. Bai, K.; Huang, Q.; Zhang, J.; He, J.; Zhang, L.; Wang, T. Supplemental effects of probiotic Bacillus subtilis $\mathrm{fmbJ}$ on growth performance, antioxidant capacity, and meat quality of broiler chickens. Poult. Sci. 2017, 96, 74-82. [CrossRef]

36. Fathi, M.M.; Ebeid, T.A.; Al-Homidan, I.; Soliman, N.K.; Abou-Emera, O.K. Influence of probiotic supplementation on immune response in broilers raised under hot climate. Br. Poult. Sci. 2017, 58, 512-516. [CrossRef] 
37. Alagawany, M.; Abd El-Hack, M.E.; Farag, M.R.; Sachan, S.; Karthik, K.; Dhama, K. The use of probiotics as eco-friendly alternatives for antibiotics in poultry nutrition. Environ. Sci. Pollut. Res. 2018, 25, 10611-10618. [CrossRef]

38. Chichlowski, M.; Croom, W.J.; Edens, F.W.; McBride, B.W.; Qiu, R.; Chiang, C.C.; Daniel, L.R.; Havenstein, G.B.; Koci, M.D. Microarchitecture and Spatial Relationship Between Bacteria and Ileal, Cecal, and Colonic Epithelium in Chicks Fed a Direct-Fed Microbial, PrimaLac, and Salinomycin. Poult. Sci. 2007, 86, 1121-1132. [CrossRef]

39. Timmerman, H.M.; Veldman, A.; van den Elsen, E.; Rombouts, F.M.; Beynen, A.C. Mortality and Growth Performance of Broilers Given Drinking Water Supplemented with Chicken-Specific Probiotics. Poult. Sci. 2006, 85, 1383-1388. [CrossRef]

40. Awad, W.A.; Ghareeb, K.; Böhm, J. Effect of addition of a probiotic micro-organism to broiler diet on intestinal mucosal architecture and electrophysiological parameters: Addition of probiotic micro-organism to broiler diet. J. Anim. Physiol. Anim. Nutr. 2010, 94, 486-494. [CrossRef]

41. Messaoudi, S.; Manai, M.; Kergourlay, G.; Prévost, H.; Connil, N.; Chobert, J.-M.; Dousset, X. Lactobacillus salivarius: Bacteriocin and probiotic activity. Food Microbiol. 2013, 36, 296-304. [CrossRef]

42. Olnood, C.G.; Beski, S.S.M.; Choct, M.; Iji, P.A. Novel probiotics: Their effects on growth performance, gut development, microbial community and activity of broiler chickens. Anim. Nutr. 2015, 1, 184-191. [CrossRef]

43. Nakphaichit, M.; Thanomwongwattana, S.; Phraephaisarn, C.; Sakamoto, N.; Keawsompong, S.; Nakayama, J.; Nitisinprasert, S. The effect of including Lactobacillus reuteri KUB-AC5 during post-hatch feeding on the growth and ileum microbiota of broiler chickens. Poult. Sci. 2011, 90, 2753-2765. [CrossRef]

44. Mountzouris, K.C.; Tsitrsikos, P.; Palamidi, I.; Arvaniti, A.; Mohnl, M.; Schatzmayr, G.; Fegeros, K. Effects of probiotic inclusion levels in broiler nutrition on growth performance, nutrient digestibility, plasma immunoglobulins, and cecal microflora composition. Poult. Sci. 2010, 89, 58-67. [CrossRef]

45. Mikulski, D.; Jankowski, J.; Mikulska, M.; Demey, V. Effects of dietary probiotic (Pediococcus acidilactici) supplementation on productive performance, egg quality, and body composition in laying hens fed diets varying in energy density. Poult. Sci. 2020, 99, 2275-2285. [CrossRef]

46. Mikulski, D.; Jankowski, J.; Naczmanski, J.; Mikulska, M.; Demey, V. Effects of dietary probiotic (Pediococcus acidilactici) supplementation on performance, nutrient digestibility, egg traits, egg yolk cholesterol, and fatty acid profile in laying hens. Poult. Sci. 2012, 91, 2691-2700. [CrossRef]

47. Martínez, E.A.; Babot, J.D.; Lorenzo-Pisarello, M.J.; Apella, M.C.; Chaia, A.P. Feed supplementation with avian Propionibacterium acidipropionici contributes to mucosa development in early stages of rearing broiler chickens. Benef. Microbes 2016, 7, 687-698. [CrossRef]

48. Hassanein, S.; Soliman, N. Effect of Probiotic (Saccharomyces cerevisiae) Adding to Diets on Intestinal Microflora and Performance of Hy-Line Layers Hens. J. Am. Sci. 2010, 6, 159-169.

49. Neijat, M.; Shirley, R.B.; Barton, J.; Thiery, P.; Welsher, A.; Kiarie, E. Effect of dietary supplementation of Bacillus subtilis DSM29784 on hen performance, egg quality indices, and apparent retention of dietary components in laying hens from 19 to 48 weeks of age. Poult. Sci. 2019, 98, 5622-5635. [CrossRef]

50. He, T.; Long, S.; Mahfuz, S.; Wu, D.; Wang, X.; Wei, X.; Piao, X. Effects of Probiotics as Antibiotics Substitutes on Growth Performance, Serum Biochemical Parameters, Intestinal Morphology, and Barrier Function of Broilers. Animals 2019, 9, 985. [CrossRef]

51. Manafi, M.; Khalaji, S.; Hedayati, M.; Pirany, N. Efficacy of Bacillus subtilis and bacitracin methylene disalicylate on growth performance, digestibility, blood metabolites, immunity, and intestinal microbiota after intramuscular inoculation with Escherichia coli in broilers. Poult. Sci. 2017, 96, 1174-1183. [CrossRef]

52. Chen, K.-L.; Kho, W.-L.; You, S.-H.; Yeh, R.-H.; Tang, S.-W.; Hsieh, C.-W. Effects of Bacillus subtilis var. natto and Sacharomyces cerevisiae mixed fermented feed on the enhanced growth performance of broilers. Poult. Sci. 2009, 88, 309-315. [CrossRef]

53. Jin, L.Z.; Ho, Y.W.; Abdullah, N.; Jalaludin, S. Digestive and bacterial enzyme activities in broilers fed diets supplemented with Lactobacillus cultures. Poult. Sci. 2000, 79, 886-891. [CrossRef]

54. Jazi, V.; Foroozandeh, A.D.; Toghyani, M.; Dastar, B.; Rezaie Koochaksaraie, R.; Toghyani, M. Effects of Pediococcus acidilactici, mannan-oligosaccharide, butyric acid and their combination on growth performance and intestinal health in young broiler chickens challenged with Salmonella Typhimurium. Poult. Sci. 2018, 97, 2034-2043. [CrossRef] 
55. Singh, A.K.; Tiwari, U.P.; Berrocoso, J.D.; Dersjant-Li, Y.; Awati, A.; Jha, R. Effects of a combination of xylanase, amylase and protease, and probiotics on major nutrients including amino acids and non-starch polysaccharides utilization in broilers fed different level of fibers. Poult. Sci. 2019, 98, 5571-5581. [CrossRef]

56. Niewold, T.A. The Nonantibiotic Anti-Inflammatory Effect of Antimicrobial Growth Promoters, the Real Mode of Action? A Hypothesis. Poult. Sci. 2007, 86, 605-609. [CrossRef] [PubMed]

57. Jadhav, K.; Katoch, S.; Sharma, V.K.; Mane, B.G. Probiotics in Broiler Poultry Feeds: A Review. J. Anim. Nutr. Physiol. 2015, 1, 4-16.

58. Gheorghe, A.; Tabuc, C.; Habeanu, M.; Dumitru, M.; Lefter, N.A. Effect of dietary supplementation with probiotic mixture based on Lactobacillus strains on performance, gastrointestinal development and ileal microflora in broilers. J. Biotechnol. 2018, 280, S41. [CrossRef]

59. Deng, Q.; Shi, H.; Luo, Y.; Zhao, H.; Liu, N. Effect of dietary Lactobacilli mixture on Listeria monocytogenes infection and virulence property in broilers. Poult. Sci. 2020, 99, 3655-3662. [CrossRef]

60. Lokapirnasari, W.P.; Sahidu, A.M.; Maslachah, L.; Sabdoningrum, E.K.; Yulianto, A.B. Effect of Lactobacillus Casei and Lactobacillus acidophilus in Laying Hens Challenged by Escherichia coli Infection. Sains Malays. 2020, 49, 1237-1244. [CrossRef]

61. Ipek, A.; Sozcu, A.; Akay, V. 1012 Effects of dietary inclusion of probiotics and prebiotics (SynerAll) on growth performance and serum biochemical parameters in broilers. J. Anim. Sci. 2016, 94, 484-485. [CrossRef]

62. Murugesan, G.R.; Persia, M.E. Influence of a direct-fed microbial and xylanase enzyme on the dietary energy uptake efficiency and performance of broiler chickens: Feed additives on broiler energy metabolism. J. Sci. Food Agric. 2015, 95, 2521-2527. [CrossRef]

63. Anwar, H.; Rahman, Z.U. Efficacy of protein, symbiotic and probiotic supplementation on production performance and egg quality characteristics in molted layers. Trop. Anim. Health Prod. 2016, 48, 1361-1367. [CrossRef]

64. Delgado, S.; Sánchez, B.; Margolles, A.; Ruas-Madiedo, P.; Ruiz, L. Molecules Produced by Probiotics and Intestinal Microorganisms with Immunomodulatory Activity. Nutrients 2020, 12, 391. [CrossRef]

65. Flores, C.; Williams, M.; Pieniazek, J.; Dersjant-Li, Y.; Awati, A.; Lee, J.T. Direct-fed microbial and its combination with xylanase, amylase, and protease enzymes in comparison with AGPs on broiler growth performance and foot-pad lesion development. J. Appl. Poult. Res. 2016, 25, 328-337. [CrossRef]

66. Momtazan, R.; Moravej, H.; Zaghari, M.; Taheri, H. A note on the effects of a combination of an enzyme complex and probiotic in the diet on performance of broiler chickens. Ir. J. Agric. Food Res. 2011, 50, $249-254$. [CrossRef]

67. Zaghari, M.; Sarani, P.; Hajati, H. Comparison of two probiotic preparations on growth performance, intestinal microbiota, nutrient digestibility and cytokine gene expression in broiler chickens. J. Appl. Anim. Res. 2020, 48, 166-175. [CrossRef]

68. Sohail, M.U.; Hume, M.E.; Byrd, J.A.; Nisbet, D.J.; Shabbir, M.Z.; Ijaz, A.; Rehman, H. Molecular analysis of the caecal and tracheal microbiome of heat-stressed broilers supplemented with prebiotic and probiotic. Avian Pathol. 2015, 44, 67-74. [CrossRef] [PubMed]

69. Pan, C.; Zhao, Y.; Liao, S.F.; Chen, F.; Qin, S.; Wu, X.; Zhou, H.; Huang, K. Effect of Selenium-Enriched Probiotics on Laying Performance, Egg Quality, Egg Selenium Content, and Egg Glutathione Peroxidase Activity. J. Agric. Food Chem. 2011, 59, 11424-11431. [CrossRef] [PubMed]

70. Xiang, Q.; Wang, C.; Zhang, H.; Lai, W.; Wei, H.; Peng, J. Effects of Different Probiotics on Laying Performance, Egg Quality, Oxidative Status, and Gut Health in Laying Hens. Animals 2019, 9, 1110. [CrossRef]

71. Shroyer, N.F.; Kocoshis, S.A. Anatomy and Physiology of the Small and Large Intestines. In Pediatric Gastrointestinal and Liver Disease; Elsevier: Amsterdam, The Netherlands, 2011; pp. 324-336.e2. ISBN 978-1-4377-0774-8.

72. Buckley, A.; Turner, J.R. Cell Biology of Tight Junction Barrier Regulation and Mucosal Disease. Cold Spring Harb. Perspect. Biol. 2018, 10, a029314. [CrossRef]

73. Meyer, M.M.; Fries-Craft, K.A.; Bobeck, E.A. Composition and inclusion of probiotics in broiler diets alter intestinal permeability and spleen immune cell profiles without negatively affecting performance1. J. Anim. Sci. 2020, 98, skz383. [CrossRef] 
74. Song, J.; Xiao, K.; Ke, Y.L.; Jiao, L.F.; Hu, C.H.; Diao, Q.Y.; Shi, B.; Zou, X.T. Effect of a probiotic mixture on intestinal microflora, morphology, and barrier integrity of broilers subjected to heat stress. Poult. Sci. 2014, 93, 581-588. [CrossRef]

75. Wealleans, A.L.; Sirukhi, M.; Egorov, I.A. Performance, gut morphology and microbiology effects of a Bacillus probiotic, avilamycin and their combination in mixed grain broiler diets. Br. Poult. Sci. 2017, 58, 523-529. [CrossRef]

76. Kemgang, T.S.; Kapila, S.; Shanmugam, V.P.; Kapila, R. Cross-talk between probiotic lactobacilli and host immune system. J. Appl. Microbiol. 2014, 117, 303-319. [CrossRef]

77. Rhayat, L.; Jacquier, V.; Brinch, K.S.; Nielsen, P.; Nelson, A.; Geraert, P.-A.; Devillard, E. Bacillus subtilis s train specificity affects performance improvement in broilers. Poult. Sci. 2017, 96, 2274-2280. [CrossRef] [PubMed]

78. Ahmed, S.T.; Mun, H.-S.; Islam, M.M.; Kim, S.-S.; Hwang, J.-A.; Kim, Y.-J.; Yang, C.-J. Effects of Citrus junos by-products fermented with multistrain probiotics on growth performance, immunity, caecal microbiology and meat oxidative stability in broilers. Br. Poult. Sci. 2014, 55, 540-547. [CrossRef] [PubMed]

79. Cox, C.M.; Dalloul, R.A. Immunomodulatory role of probiotics in poultry and potential in ovo application. Benef. Microbes 2015, 6, 45-52. [CrossRef] [PubMed]

80. Yitbarek, A.; Echeverry, H.; Munyaka, P.; Rodriguez-Lecompte, J.C. Innate immune response of pullets fed diets supplemented with prebiotics and synbiotics. Poult. Sci. 2015, 94, 1802-1811. [CrossRef] [PubMed]

81. Teo, A.Y.; Tan, H.-M. Evaluation of the Performance and Intestinal Gut Microflora of Broilers Fed on Corn-Soy Diets Supplemented with Bacillus subtilis PB6 (CloSTAT). J. Appl. Poult. Res. 2007, 16, 296-303. [CrossRef]

82. Higgins, S.E.; Erf, G.F.; Higgins, J.P.; Henderson, S.N.; Wolfenden, A.D.; Gaona-Ramirez, G.; Hargis, B.M. Effect of Probiotic Treatment in Broiler Chicks on Intestinal Macrophage Numbers and Phagocytosis of Salmonella Enteritidis by Abdominal Exudate Cells. Poult. Sci. 2007, 86, 2315-2321. [CrossRef] [PubMed]

83. Aliakbarpour, H.R.; Chamani, M.; Rahimi, G.; Sadeghi, A.A.; Qujeq, D. The Bacillus subtilis and Lactic Acid Bacteria Probiotics Influences Intestinal Mucin Gene Expression, Histomorphology and Growth Performance in Broilers. Asian Australas. J. Anim. Sci. 2012, 25, 1285-1293. [CrossRef] [PubMed]

84. Jha, R.; Singh, A.K.; Yadav, S.; Berrocoso, J.F.D.; Mishra, B. Early Nutrition Programming (in ovo and Post-Hatch Feeding) as a Strategy to Modulate Gut Health of Poultry. Front. Vet. Sci. 2019, 6, 82. [CrossRef]

85. Oakley, B.B.; Kogut, M.H. Spatial and Temporal Changes in the Broiler Chicken Cecal and Fecal Microbiomes and Correlations of Bacterial Taxa with Cytokine Gene Expression. Front. Vet. Sci. 2016, 3. [CrossRef]

86. Sureshkumar, S.; Jung, S.K.; Kim, D.; Oh, K.B.; Yang, H.; Lee, H.C.; Jo, Y.J.; Lee, H.S.; Lee, S.; Byun, S.J. Administration of L. salivarius expressing $3 \mathrm{D} 8 \mathrm{scFv}$ as a feed additive improved growth performance, immune homeostasis and gut microbiota in chickens. Anim. Sci. J. 2020. [CrossRef]

87. Diaz Carrasco, J.M.; Casanova, N.A.; Fernández Miyakawa, M.E. Microbiota, Gut Health and Chicken Productivity: What Is the Connection? Microorganisms 2019, 7, 374. [CrossRef] [PubMed]

88. Shang, Y.; Kumar, S.; Oakley, B.; Kim, W.K. Chicken Gut Microbiota: Importance and Detection Technology. Front. Vet. Sci. 2018, 5, 254. [CrossRef] [PubMed]

89. Asghar, S.; Arif, M.; Nawaz, M.; Muhammad, K.; Ali, M.A.; Ahmad, M.D.; Iqbal, S.; Anjum, A.A.; Khan, M.; Nazir, J. Selection, characterisation and evaluation of potential probiotic Lactobacillus spp. isolated from poultry droppings. Benef. Microbes 2016, 7, 35-44. [CrossRef] [PubMed]

90. Adhikari, B.; Kwon, Y.M. Characterization of the Culturable Subpopulations of Lactobacillus in the Chicken Intestinal Tract as a Resource for Probiotic Development. Front. Microbiol. 2017, 8, 1389. [CrossRef] [PubMed]

91. Wang, Y.; Sun, J.; Zhong, H.; Li, N.; Xu, H.; Zhu, Q.; Liu, Y. Effect of probiotics on the meat flavour and gut microbiota of chicken. Sci. Rep. 2017, 7, 6400. [CrossRef] [PubMed]

92. Mountzouris, K.C.; Tsirtsikos, P.; Kalamara, E.; Nitsch, S.; Schatzmayr, G.; Fegeros, K. Evaluation of the Efficacy of a Probiotic Containing Lactobacillus, Bifidobacterium, Enterococcus, and Pediococcus Strains in Promoting Broiler Performance and Modulating Cecal Microflora Composition and Metabolic Activities. Poult. Sci. 2007, 86, 309-317. [CrossRef] [PubMed]

93. Cengiz, Ö.; Köksal, B.H.; Tatlı, O.; Sevim, Ö.; Ahsan, U.; Üner, A.G.; Ulutaş, P.A.; Beyaz, D.; Büyükyörük, S.; Yakan, A.; et al. Effect of dietary probiotic and high stocking density on the performance, carcass yield, gut microflora, and stress indicators of broilers. Poult. Sci. 2015, 94, 2395-2403. [CrossRef]

94. Neveling, D.P.; van Emmenes, L.; Ahire, J.J.; Pieterse, E.; Smith, C.; Dicks, L.M.T. Effect of a Multi-Species Probiotic on the Colonisation of Salmonella in Broilers. Probiotics Antimicrob. Proteins 2019. [CrossRef] 
95. Jeong, H.; Arif, B.; Caetano-Anollés, G.; Kim, K.M.; Nasir, A. Horizontal gene transfer in human-associated microorganisms inferred by phylogenetic reconstruction and reconciliation. Sci. Rep. 2019, 9, 5953. [CrossRef]

96. Das, D.J.; Shankar, A.; Johnson, J.B.; Thomas, S. Critical insights into antibiotic resistance transferability in probiotic Lactobacillus. Nutrition 2020, 69, 110567. [CrossRef]

97. Gueimonde, M.; Sánchez, B.; de los Reyes-Gavilán, C.G.; Margolles, A. Antibiotic resistance in probiotic bacteria. Front. Microbiol. 2013, 4. [CrossRef] [PubMed]

98. Zheng, M.; Zhang, R.; Tian, X.; Zhou, X.; Pan, X.; Wong, A. Assessing the Risk of Probiotic Dietary Supplements in the Context of Antibiotic Resistance. Front. Microbiol. 2017, 8, 908. [CrossRef] [PubMed]

(C) 2020 by the authors. Licensee MDPI, Basel, Switzerland. This article is an open access article distributed under the terms and conditions of the Creative Commons Attribution (CC BY) license (http://creativecommons.org/licenses/by/4.0/). 